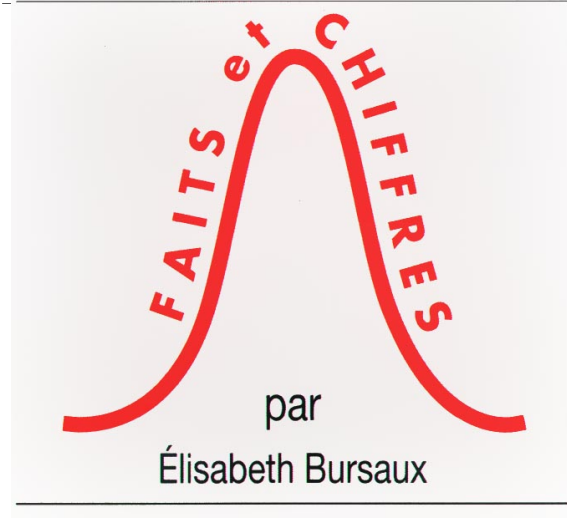

médecine/sciences $1996 ; 12: 820-1$

\title{
Dynamique du VIH-1 in vivo
}

\section{RÉFÉRENCES}

1. Perelson AS, Neumann AU, Markowitz M, Leonard JM, Ho DD. HIV-1 dynamics in vivo: virion clearance rate, infected cell life-span, and viral generation time. Science $1996 ; 271: 1582-6$.

2. Ho DD, Neumann AU, Perelson AS Chen W, Leonard JM, Markowitz M. Rapid turnover of plasma virions and CD4 lymphocytes in HIV-1 infection. Nature 1995 ; $373: 123-6$.

3. Wei X, Gosh SJ, Taylor ME, et al. (12 auteurs). Nature $1995 ; 373$ : 117- 22

4. Hatton T, Zhou S, Standring DN. RNAand DNA-binding activities in hepatitis B virus capsid protein : a model for their roles in viral replication. J Virol $1992 ; 66$ :
D our espérer lutter efficacement contre le VIH, il faut en connaître beaucoup de propriétés, en particulier ses propriétés dynamiques. La concentration de particules virales VIH-1 dans le plasma dépend à chaque instant de son taux de réplication dans les cellules infectées, de son débit de fuite hors du plasma et du débit de renouvellement des cellules infectées. Étudier la dynamique des échanges in vivo est possible si on arrête à un instant précis la réplication de particules infectieuses et que l'on suive le devenir des virions. La disponibilité des inhibiteurs de protéase permet aujourd'hui ces études.

Un travail à la fois théorique et pratique a été publié très récemment dans Science qui développe un nouveau modèle mathématique permettant d'analyser la dynamique in vivo de la charge en virus VIH-1 chez cinq malades traités par le ritonavir $^{\circledR}$, un nouvel inhibiteur de protéase, à raison de $600 \mathrm{mg}$ deux fois par jour [1]. On a suivi séquentiellement la concentration plasmatique d'ARN viral: toutes les deux heures jusqu'à la sixième heure, toutes les six heures jusqu'au jour 2, puis tous les jours jusqu'au jour 7 , soit 15 mesures au cours des 7 premiers jours, ce qui permet une analyse mathématique relativement fine. Cela a, en particulier, permis de mesurer le délai pharmacologique et le délai pendant lequel les cellules infectées répliquent des virus non infectieux. Grâce à ces déterminations, les auteurs ont pu obtenir des résultats fiables sur la dynamique de chacun des constituants du système: la durée de vie moyenne du virion dans l'espace extracellulaire ( 0,3 jour $)$, le temps moyen de réplication du virus défini comme le temps qui s'écoule entre la libération d'un nouveau virion et sa réplication après avoir infecté une nouvelle cellule (2,6 jours), la durée de vie des cellules infectées, (2,2 jours) (figure 1). Tous les malades ont réagi de manière très voisine, malgré une charge virale initiale et un nombre de lymphocytes T CD4 différents (Tableau I).

La population des virions plasmatiques est remplacée à peu près toutes les 6 heures (si l'on assume que l'efficacité du ritonavir est totale, ce qui fait de ce chiffre une estimation minimale). La quantité moyenne de virions produits et libérés dans l'espace extracellulaire est au moins de $10,3.10^{9}$ par jour, une valeur quinze fois supérieure aux estimations précédentes $\left(m / s n^{\circ} 3\right.$, vol. 11, p. 486) [2], et au moins $99 \%$ de ces virus sont produits par les cellules nouvellement infectées $[2,3]$. La constante de vitesse de la clairance plasmatique des virions étant très voisine chez chacun des malades, on peut en déduire que la virémie mesurée est le reflet de la production virale, elle-même dépendant du nombre de cellules infectées productives et du nombre de virions qu'elles libèrent; le temps de génération moyen des virus mesuré à 2,6 jours suggère que chaque année se produisent 140 cycles de réplication virale. Cette réplication répétée rend 


\begin{tabular}{|c|c|c|c|c|c|c|c|c|}
\hline \multicolumn{9}{|c|}{$\begin{array}{c}\text { Tableau I } \\
\text { ÉLÉMENTS DU CALCUL DE LA DYNAMIQUEDU VIH IN VIVO }\end{array}$} \\
\hline \multicolumn{4}{|c|}{ Valeurs de base } & \multicolumn{5}{|c|}{$\begin{array}{l}\text { Valeurs calculées à partir de la relation } \\
\text { entre } V(t) \text { et la charge vitale }\end{array}$} \\
\hline & & & & \multicolumn{2}{|c|}{ Clairance des virions } & \multicolumn{2}{|c|}{$\begin{array}{c}\text { Pertes des } \\
\text { cellules infectées }\end{array}$} & \multirow[t]{2}{*}{$\begin{array}{l}\text { Production } \\
\text { des virions } \\
\left(10^{9} / \mathrm{j}\right)\end{array}$} \\
\hline Malade & Cellules CD4 & $\begin{array}{c}\text { Virions } \\
\text { plasma. } \\
\left(10^{3} \text { par } \mathrm{ml}\right)\end{array}$ & $\begin{array}{l}\text { Délai } \\
\text { pharmacolo- } \\
\text { gique (h) }\end{array}$ & (par jour) & $\begin{array}{c}\mathrm{t} 1 / 2 \\
\text { (jours) }\end{array}$ & $\stackrel{\delta}{(p a r \text { jour })}$ & $\begin{array}{c}\mathrm{t} 1 / 2 \\
\text { (jours) }\end{array}$ & \\
\hline $\begin{array}{l}1 \\
2 \\
3 \\
4 \\
5\end{array}$ & $\begin{array}{c}16 \\
408 \\
2 \\
11 \\
412\end{array}$ & $\begin{array}{c}294 \\
12 \\
52 \\
643 \\
77\end{array}$ & $\begin{array}{l}2 \\
6 \\
2 \\
6 \\
2\end{array}$ & $\begin{array}{l}3,81 \\
2,73 \\
3,68 \\
2,06 \\
3,09\end{array}$ & $\begin{array}{l}0,18 \\
0,25 \\
0,19 \\
0,34 \\
0,22\end{array}$ & $\begin{array}{l}0,26 \\
0,68 \\
0,50 \\
0,53 \\
0,50\end{array}$ & $\begin{array}{l}2,67 \\
1,02 \\
1,39 \\
1,31 \\
1,39\end{array}$ & $\begin{array}{c}12,9 \\
0,4 \\
2,9 \\
32,1 \\
3,1\end{array}$ \\
\hline $\begin{array}{l}\text { Moyenne } \\
\pm \text { SD }\end{array}$ & $\begin{array}{l}170 \\
196\end{array}$ & $\begin{array}{l}216 \\
235\end{array}$ & $\begin{array}{l}3,6 \\
2,0\end{array}$ & $\begin{array}{l}3,07 \\
0,64\end{array}$ & $\begin{array}{l}0,24 \\
0,06\end{array}$ & $\begin{array}{l}0,49 \\
0,13\end{array}$ & $\begin{array}{l}1,55 \\
0,57\end{array}$ & $\begin{array}{l}10,3 \\
11,7\end{array}$ \\
\hline
\end{tabular}

(1) $d T^{*} / d t=k V T-\delta T^{*}$

(2) $d V / d t=N \delta t^{*}-V$ où $T^{*}=$ population de cellules $T$ infectées, $T=$ population de cellules CD4, $k=$ constante de vitesse de l'infection des cellules $T$, $V(t)=$ concentration des particules virales dans le plasma au temps $t, N=$ nombre de nouveaux virions produits par cellule infectée, $\delta=$ constante de vitesse de la disparition des cellules infectées, = constante de vitesse de la clairance des virions plasmatiques.

(3) $d T^{*} / d t=k V i T-\delta T$

(4) $d V i / d t=-V$

(5) $d V n i / d t=N \delta T^{*}-V n i$, Des équations (3), (4) et (5) on déduit (6) $V(t)=V_{0} \exp (-t)+c V 0 /-\delta\{/-\delta[\exp (-\mathrm{dt})-\exp (-c t)]-\delta$ texp $(-\mathrm{t})\}$

$V=V_{j}+V_{n i}: V_{i}=$ concentration plasmatique des virions infectieux (avant traitement), $V_{n i}=$ concentration plasmatique des virions non infectieux (après le début du traitement), $V_{0}=V_{i}$ au temps $t=0$.

compte d'au moins $99 \%$ des virus plasmatiques et de la destruction très rapide des lymphocytes $\mathrm{CD} 4$.

L'intérêt de ces mesures est de donner les lignes directrices de la stratégie à adopter pour développer de

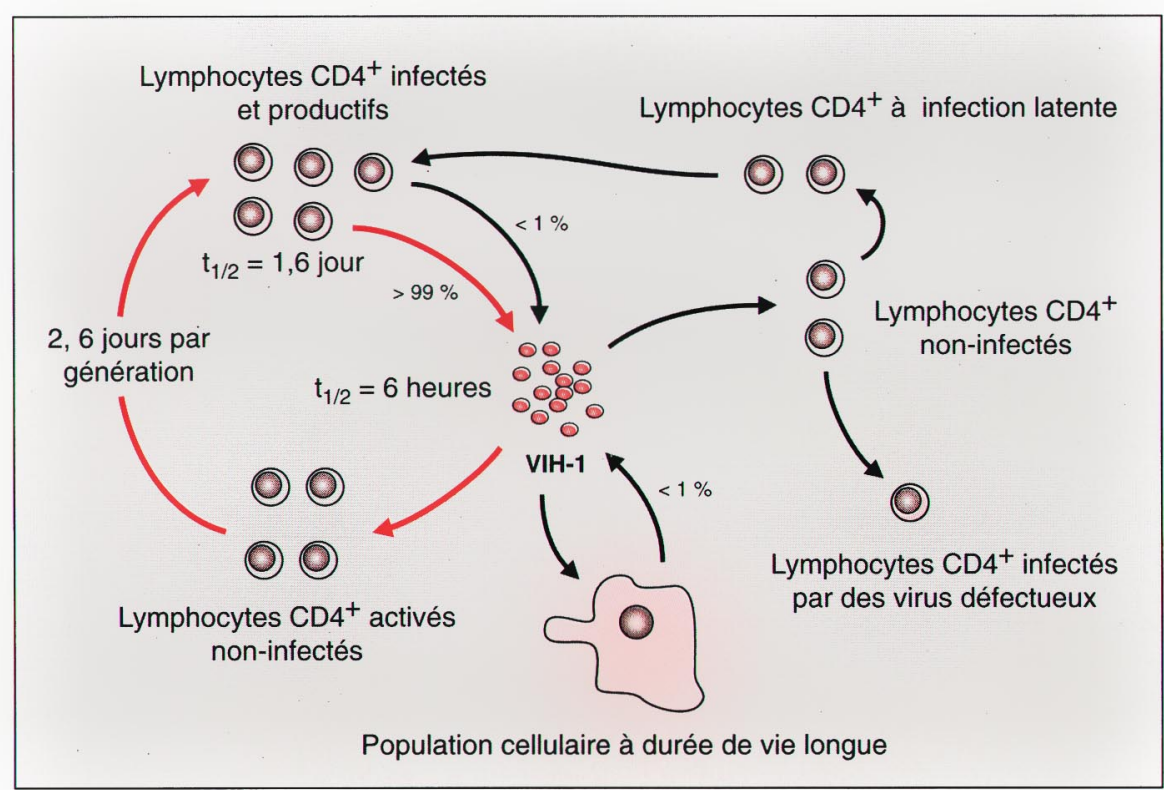

Figure 1. Représentation schématique de la dynamique de VIH-1 in vivo. Au centre est représentée la population virale plasmatique à partir de laquelle sont faites les mesures de charge virale (mesure de I'ARN viral plasmatique). La moitié des virions est renouvelée en 6 heures. Le temps de génération (2,6 jours) est mesuré comme le temps nécessaire pour que la population initiale de virions plasmatiques produise la même population de virions (non infectieux) après ritonavir. Le $t_{1,2}$ des cellules infectées (1,6 jour) est le temps nécessaire à la disparition de la moitié de ces cellules. nouveaux antiviraux $\left(\mathrm{m} / \mathrm{s} n^{\circ} 3\right.$, vol. 11, p. 486): (1) un antiviral efficace doit diminuer la charge virale plasmatique au bout de quelques jours ; (2) la conjonction de la rapidité de la vitesse de renouvellement des virus et de la vitesse de mutation du virus $\left(3,4 \cdot 10^{-5}\right.$ par paire de bases (le génome viral en compte $10^{4}$ ) et par cycle de réplication [4]) explique les échecs des traitements par monothérapie. Il semble logique d'intervenir de manière agressive si on espère le succès ; (3) les résultats présentés ici montrent que l'essentiel de la réplication active du VIH peut être éliminé en deux à trois semaines. En revanche, on ne connaît rien de la dynamique des virus des autres compartiments qui, bien qu'ils ne représentent que moins de $1 \%$ des virus plasmatiques, pourraient relancer l'infection dès que la garde thérapeutique serait abaissée. L'étude de ces autres compartiments est indispensable pour connaître la durée minimale d'observance d'un traitement pour qu'il soit efficace en permettant à ces compartiments annexes de s'épuiser 